\title{
The effects of sex steroid hormones and interleukin-1-beta on MUC1 expression in endometrial epithelial cell lines
}

\author{
A W Horne, E-N Lalani ${ }^{1}$, R A Margara ${ }^{2}$ and J O White ${ }^{3}$ \\ Simpson Centre for Reproductive Health, Royal Infirmary of Edinburgh, 51 Little France Crescent, Edinburgh EH16 \\ 4SA, UK, Departments of ${ }^{1}$ Histopathology and ${ }^{2}$ Obstetrics and Gynaecology, Imperial College, Hammersmith \\ Hospital, Du Cane Road, London W12 ONN, UK and ${ }^{3}$ The Clinical School, University of Wales Swansea, \\ Singleton Park, Swansea SA2 8PP, UK
}

Correspondence should be addressed to A Horne; Email: awhorne@hotmail.com

\begin{abstract}
Oestrogen, progesterone and paracrine signals from the embryo have been associated with the overall control of implantation. Changes in the expression of the heavily glycosylated transmembrane glycoprotein MUC1 mucin on the endometrial epithelium are also thought to be important for embryo attachment. Increased MUC1 expression has been correlated with elevated progesterone levels in the secretory phase of the menstrual cycle. Embryonic control of endometrial receptivity through changes in MUC1 expression could be achieved through the interleukin-1 system. Four endometrial epithelial cell lines (HEC1A, HEC1B, Ishikawa and RL592) were treated with oestrogen and progesterone (with or without interleukin-1-beta) and were subjected to immunocytochemistry and flow cytometric analysis to determine MUC1 production using MUC1 antibodies. HEC1A (oestrogen receptor (ER) and progesterone receptor (PR) positive) and HEC1B (ER positive and PR negative) were transfected with the MUC1 promoter, underwent similar treatment regimes and the activity of the MUC1 promoter relative to their untreated controls was determined using a chloramphenicol acetyltransferase (CAT) enzyme-linked immunoassay. Using the cell lines, we determined that endometrial MUC1 expression is up-regulated by progesterone, consistent with the in vivo increases in MUC1 related to high progesterone levels. We also revealed that neither oestrogen, nor interleukin-1-beta, appear to modulate MUC1. Progesterone-dependent regulation of MUC1 is likely to be an important factor in determining endometrial receptivity.

Reproduction (2006) 131 733-742
\end{abstract}

\section{Introduction}

The receptive status of the endometrium in embryonic implantation is a balance between the activation of adhesion molecules and the presence of a barrier that the embryo may encounter on the endometrial epithelium (Aplin 1997, Horne et al. 2002a). This process is undoubtedly influenced by maternal steroid hormones, but may also be affected by local embryonic paracrine signals (Simon \& Valbuena 1999, Simon et al. 2000).

Intrinsic heterogeneity in the glycosylation of the heavily glycosylated transmembrane glycoprotein MUC1 mucin on the endometrial epithelium could allow a local mechanism to contribute to the receptivity of the endometrium, because it may be possible that MUC1 glycoforms or the MUC1 protein core could be recognised by the embryo (Hey et al. 1994, DeLoia et al. 1998, Horne et al. 2002b, Brayman et al. 2004). Therefore, a careful evaluation of the regulation of MUC1 at the endometrial surface is necessary. Most of the data on sex steroid control of MUC1 are derived from animal and human models of endometrial MUC1 expression with respect to the menstrual cycle or human cell lines. Human in vivo data, derived from the examination of normal endometrium and endometrial carcinoma, suggest that low levels of MUC1 mRNA correlate with higher levels of plasma oestrogen and that progesterone, preceded by oestrogen priming, increases MUC1 mRNA and MUC1 protein (Hey et al. 1994, DeLoia et al. 1998, Meseguer et al. 2001). There is also evidence that progesterone receptor (PR) negativity in tumour epithelial cells is associated with increased MUC1 protein (Sivridis et al. 2002).

In vitro data from human endometrial, breast and prostate carcinoma cell lines suggest that oestrogen alone has no effect on MUC1 mRNA or MUC1 protein (Gollub et al. 1995, Botti et al. 1997, McGuckin et al. 1998, Mitchell et al. 2002). The data regarding the effect of progesterone in isolation are conflicting, but progesterone alone (as well as progesterone preceded by oestrogen priming) appears to 
increase MUC1 protein expression in some prostatic and breast carcinoma cell lines (Gollub et al. 1995, Botti et al. 1997, McGuckin et al. 1998, Mitchell et al. 2002).

The molecular mechanism of regulation of MUC1 under these circumstances remains unknown. Analyses of the MUC1 promoter have identified many potential binding sites for transcription regulating factors - including GC boxes, Sp1 sites, and several oestrogen receptor (OR) and PR sites (Lancaster et al. 1990, Abe \& Kufe 1993, Kovarik et al. 1993, 1996, Zaretsky et al. 1999, Morris \& TaylorPapadimitriou 2001). Sex steroids could therefore be involved in the regulation of MUC1 transcription either by directly interacting with the MUC1 promoter or indirectly by stimulating or repressing other transcription factors.

MUC1 mRNA and MUC1 protein are up-regulated by the embryo during the apposition phase but locally downregulated at attachment sites (Meseguer et al. 2001). It is not known precisely how this effect is mediated but it has been postulated that the cytokine, interleukin-1-beta (IL-1 $\beta)$, and its receptor, contribute to the regulation of molecules, such as MUC1, to provide the interface between the embryo and endometrium (Simon et al. 1995, 1998, Simon \& Valbuena 1999). IL-1 $\beta$ produced by cultured human embryos and high concentrations of IL-1 $\beta$ $(>80 \mathrm{pg} / \mathrm{ml})$ in the conditioned media of cultured embryos have been correlated with successful human implantation after in vitro fertilisation (Zolti et al. 1991, Baranao et al. 1992). IL-1 bioactivity in human serum also reaches maximal levels during the secretory phase (Cannon \& Dinarello 1985).

This study was undertaken to investigate the influence of oestrogen and progesterone, in the absence and presence of IL-1 $\beta$, on MUC1 expression in endometrial epithelial cell lines.

\section{Materials and Methods}

Four endometrial epithelial carcinoma cell lines were used: HEC1A, HEC1B, Ishikawa and RL952. The cell lines were treated with a range of sex hormone regimes, with or without IL-1 $\beta$, and were subjected to immunocytochemistry and flow cytometric analysis to determine MUC1 protein expression using the monoclonal antibodies (Mabs) HMFG1, HMFG2, SM3 and CT1. Two of the cell lines, HEC1A (ER and PR positive) and HEC1B (ER positive and PR negative) were transfected with the MUC1 promoter. They underwent similar treatment regimes and the activity of the MUC1 promoter relative to their untreated controls was determined using a chloramphenicol acetyltransferase (CAT) enzyme-linked immunoassay.

\section{Antibodies}

The MUC1 Mabs used for this study included HMFG1, HMFG2 and SM3 (all IgG1). HMFG1 and HMFG2 (both from SkyBio, Wyboston, UK) react strongly with malignant tissues, but are not cancer specific and react equally well with normal epithelial tissues (Taylor-Papadimitriou et al. 1981, Hilkens et al. 1984, Xing et al. 1989). The preferred target for these antibodies is located within the extracellular domain of MUC1 which includes one possible O-glycosylation site (Price et al. 1991). The Mabs react differently with MUC1 due to the glycosylation, which can hide peptide epitopes (Burchell \& Taylor-Papadimitriou 1993, Ho et al. 1995). CT1 (a kind gift from Dr Joy Burchell, CR UK, London, UK) is the polyclonal antiserum to the cytoplasmic tail of MUC1 (Pemberton et al. 1992). It is one of a few reagents whose reactivity with the MUC1 mucin is independent of the O-glycosylation seen in the extracellular domain. The anti-PR antibody used was a mouse monoclonal (IgG1) which recognises the $\mathrm{N}$-terminal region of both the $A$ and $B$ forms of PR (Novocastra, Peterborough, UK) (Giri et al. 1998, Peterson 2000).

\section{Endometrial epithelial cell lines}

The endometrial epithelial carcinoma cell lines HEC1A, HEC1B, Ishikawa and RL952 have previously been extensively characterised (Kuramoto 1972, Kuramoto et al. 1972, Way et al. 1983, Gollub et al. 1993, 1995). All cell lines express ER but HEC1B cells have been shown to be devoid of immunoreactive PR (Gao et al. 1994). Furthermore, an induction in the activity of progesterone-responsive reporter plasmids has only been observed in HEC1B cells in the presence of co-transfected PR-B, and not in untransfected cells (Bamberger et al. 1996). Prior to the following experiments and following treatments, we confirmed that HEC1A cells were PR positive and that HEC1B cells were PR negative (and that PR was not induced by hormonal treatment), using standard Western blotting techniques and the above anti-PR antibody (data not shown).

\section{General maintenance of cell lines}

All cell lines were grown in phenol-red-free Dulbecco's modified Eagle's medium (DMEM) supplemented with stripped foetal bovine serum (FBS) (both from Gibco) and penicillin-streptomycin-amphotericin B mixture (at a final concentration of $100 \mathrm{U}, 100 \mathrm{mg} / \mathrm{ml}$ and $0.25 \mathrm{mg} / \mathrm{ml}$ respectively) to limit infections. Cells were routinely split at $80 \%$ confluence using trypsin-EDTA $(0.05 \% \mathrm{v} / \mathrm{v}$ and $0.53 \mathrm{mM}$ respectively; in Hank's balanced salt solution without calcium and magnesium) (Gibco) or versene (CR UK), routinely sub-cultured at between $1: 6$ and $1: 10$ depending upon the cell line, and the medium was routinely changed every $72 \mathrm{~h}$. Prior to immunocytochemistry, the cell lines were grown to $80 \%$ confluency, trypsinised and re-suspended in fresh DMEM containing 10\% stripped FBS. The cell suspension was further diluted such that $300 \mu \mathrm{l}$ aliquoted four-well slides produced approximately $30 \%$ confluency after $24 \mathrm{~h}$ incubation at $37^{\circ} \mathrm{C}$. At this stage, the DMEM was replaced with DMEM containing $2 \%$ stripped FBS. After $48 \mathrm{~h}$, incubations with sex steroids and/or IL-1 $\beta$ were started. Prior to flow cytometry, cells 
were grown in T75 flasks in DMEM containing 10\% stripped FBS. When the cells got to $30 \%$ confluency, the DMEM was replaced with DMEM containing $2 \%$ FBS. After $48 \mathrm{~h}$ in $2 \%$ DMEM, incubations with sex steroids, with or without IL-1 $\beta$ were started. Culture medium and treatments were changed daily.

\section{Cell treatments}

The cell lines were incubated for a range of time periods with different concentrations of sex steroids, with or without IL-1 $\beta$ prior to immunocytochemistry and flow cytometry to examine the effect of the treatments on MUC1 mucin expression, and transfection experiments to measure their effect on MUC1 promoter activity. The sex steroids (ICN Biomedicals, OH, USA) and IL- $1 \beta$ (R\&D Systems, Abingdon, UK) were diluted to stock solutions of $1000 \times$ final concentration desired in $100 \%$ ethanol and stored at $-20^{\circ} \mathrm{C}$ and $-70{ }^{\circ} \mathrm{C}$ respectively. Each cell line was treated for $48,72,96$ or $192 \mathrm{~h}$ with either 17-beta oestradiol or progesterone alone at either $10^{-10}, 10^{-8}$ or $10^{-6} \mathrm{M}$, and also individually treated with a combination of 17-beta oestradiol $\left(10^{-10} \mathrm{M}\right)$ for $96 \mathrm{~h}$ followed by 17-beta oestradiol and progesterone $\left(10^{-7} \mathrm{M}\right)$ for a further $96 \mathrm{~h}$. The same cells were subjected to the addition of IL-1 $\beta$ at 10 and $100 \mathrm{pg} / \mathrm{ml}$ for the last $48 \mathrm{~h}$ of their treatments. Mock treatment with ethanol was used as a negative control. Prior to treatment, cells were incubated for $48 \mathrm{~h}$ in $2 \%$ stripped FBS and were maintained in this concentration of FBS for the duration of the treatment. All concentrations and regimes used are comparable with those established in previous reports and with physiological ranges (Gollub et al. 1995, McGuckin et al. 1998, Mitchell et al. 2002).

\section{Immunocytochemistry}

Following hormone treatment, slides were washed with PBS, fixed with $-20^{\circ} \mathrm{C}$ methanol:acetone $(1: 1)$ for $10 \mathrm{~min}$ and air-dried, then stored at $-70^{\circ} \mathrm{C}$; prior to use the slides were equilibrated to room temperature for $5 \mathrm{~min}$. The slides were blocked with normal rabbit (goat for CT1) serum (Dako, Cambridge, UK), diluted 1 in 10 in $0.1 \%$ $\mathrm{v} / \mathrm{v}$ bovine albumin in PBS (PBS diluent), for $10 \mathrm{~min}$. HMFG1, HMFG2, SM3 and CT1 (all 1 in 500 dilution in PBS diluent), or PBS diluent alone, were then applied to the sections and left overnight at $4{ }^{\circ} \mathrm{C}$. After washing with PBS, a biotinylated rabbit anti-mouse (goat anti-rabbit for CT1) immunoglobulin (Dako) (diluted 1 in 200 in PBS diluent) was applied for $30 \mathrm{~min}$. This was followed by incubation with the avidin-biotin complex (Dako) for $30 \mathrm{~min}$ before visualisation with diaminobenzidine $(2 \mathrm{mg} / \mathrm{ml})$ in PBS with the addition of hydrogen peroxide (1 in 2000) shortly before use. The reaction was terminated after $10 \mathrm{~min}$ by washing in tap water. The slides were counterstained in Mayer's haematoxylin for $10 \mathrm{~s}$ and mounted in Pertex.

\section{Flow cytometry}

Following hormone treatment, cells were detached with versene plus gentle agitation and washed twice at $4{ }^{\circ} \mathrm{C}$ using the washing buffer (PBS containing 1\% FBS). Samples were then re-suspended in $75 \mathrm{ml} \mathrm{MUC1}$ antibody (diluted 1 in 500 in washing buffer) and incubated at $4{ }^{\circ} \mathrm{C}$ for $1 \mathrm{~h}$. One additional sample per cell line was incubated with PBS alone instead of antibody, which served as a negative control. After washing, samples were re-suspended in $300 \mathrm{ml}$ fluorescein isothyanate (FITC)-labelled secondary antibody, and incubated at $4{ }^{\circ} \mathrm{C}$ for $45 \mathrm{~min}$. Following further washing, samples were re-suspended in $500 \mathrm{ml} \mathrm{PBS}$ containing $2 \%$ neutral buffered formalin. Flow cytometric analysis was performed on a Coulter Epics XL (Beckman Coulter, High Wycombe, UK). Gating parameters were set to exclude clumped or dead cells, and 20000 events within the gated area were counted per individual experiment. Each experiment was performed in triplicate.

\section{Transfection of cells with MUC1 promoter}

The MUC1 promoter construct (Kovarik et al. 1993) ('-1401 to +33 bp' sequence; kind gift from Dr Sandra Gendler, Rochester, NY, USA) was linked to the CAT reporter gene (Alam \& Cook 1990). To examine MUC1 promoter activity in HEC1A and HEC1B cells, the cell lines underwent a modified treatment regime using the same range of concentrations of sex steroid hormones as previously (either 17-beta oestradiol or progesterone between $10^{-6}$ and $10^{-10} \mathrm{M}$ ), but for $192 \mathrm{~h}$. Cell lines were also treated sequentially with 17-beta oestradiol for $96 \mathrm{~h}$ followed by 17-beta oestradiol and progesterone $\left(10^{-7} \mathrm{M}\right)$ for a further $96 \mathrm{~h}$. The same cells were subjected to the addition of IL-1 $\beta$ at 10 and $100 \mathrm{pg} / \mathrm{ml}$ for the last $48 \mathrm{~h}$ of their treatments. All transfections were performed $48 \mathrm{~h}$ prior to cell harvesting using the calcium phosphate precipitation method, with reagents from a mammalian transfection kit (Promega). The cells were transfected with the MUC1 promoter construct for $6 \mathrm{~h}$ in DMEM containing 5\% stripped FBS. The cells were then washed and the medium replaced with fresh DMEM containing 2\% stripped FBS with the appropriate treatment. The cells were then cultured until immunoassay. Transfections were performed in triplicate. MUC1 promoter activity was measured using a CAT enzymelinked immunoassay (Roche), according to the manufacturer's instructions. The absorbance of the sample (directly related to the level of CAT present in the medium supernatant) was measured using the OPTImax tunable microplate reader (Molecular Devices, Wokingham, UK) and analysed using SOFTmax PRO computer software (Molecular Devices).

\section{Statistical analysis}

Flow cytometric data were analysed as follows. A plot of fluorescent intensity versus frequency was integrated to 
obtain a flow cytometric profile corresponding to overall MUC1 expression in each sample. The increases in expression demonstrated with exposure to the different treatment protocols reflect a rightward shift in these curves, i.e. an increase in mean intensity. To allow comparison between each of the treatment protocols in Figs 2 and 3, MUC1 expression (the area under the curve) is expressed as a percentage of MUC1 expression in control medium (which was set at $100 \%$ ). For statistical analysis, it was found that the variables of interest for particular treatments were more stable when expressed as ratios with the 'control' values of the variable. The ANOVA were therefore carried out on those ratios. Consequently, in Tables 1 to 3 , the difference between the tabulated figure and 1.0 represents the proportionate increase (or decrease) corresponding to the treatment. The $P$ value quoted for each analysis provides a guide for the presence of any systematic differences among the various treatments levels.

Transfection data were analysed as follows. Each cell treatment resulted in a different absorbance reading, which directly related to the CAT level in the cells. Using a range of pre-determined standards, the resulting absorbance for each cell line and each treatment was converted to give a value for the level of CAT activity. As each transfection was performed in duplicate and each CAT assay in triplicate, this resulted in six values for each treatment. The resulting CAT level (in $\mathrm{ng} / \mathrm{ml}$ ) for each treatment was thus expressed as a mean \pm S.D. Statistical differences between treatments and controls were determined by a one-tailed, unpaired $t$ test $(P<0.05$ was considered significant).

\section{Results}

\section{Immunocytochemistry for qualitative analysis of MUC1 production in stimulated endometrial epithelial cell lines}

All cell lines appeared positive for MUC1 showing a cytoplasmic expression pattern with nuclear sparing. It was not possible to differentiate separate membraneous expression from the cytoplasmic staining. None of the above cell lines showed any demonstrable changes in MUC1 expression at the light microscope level following any of the sex steroid hormone regimes compared with their controls. The majority of the Ishikawa cells showed an expression pattern of moderate intensity with HMFG1, HMFG2 and CT1. The pattern observed with SM3 was less intense and very heterogeneous. RL952 showed a characteristic 'patchwork' effect, with different groups of cells staining with different intensity with all four of the MUC1 Mabs. The expression pattern for the HEC1A cell

Table 1 Demonstration of the effects of the concentration of oestrogen and progesterone stimulation on MUC1 production in HEC1A and HEC1B cells using flow cytometric analysis and HMFG1 and CT1 (independent of time).

\begin{tabular}{|c|c|c|c|c|c|c|c|c|}
\hline & \multicolumn{4}{|c|}{ HEC1A cell line } & \multicolumn{4}{|c|}{ HEC1B cell line } \\
\hline & \multicolumn{2}{|c|}{ Oestrogen } & \multicolumn{2}{|c|}{ Progesterone } & \multicolumn{2}{|c|}{ Oestrogen } & \multicolumn{2}{|c|}{ Progesterone } \\
\hline & HMFG1 & CT1 & HMFG1 & CT1 & HMFG1 & CT1 & HMFG1 & CT1 \\
\hline \multicolumn{9}{|l|}{ Concentration } \\
\hline $10^{-10} \mathrm{M}$ & 1.250 & 1.189 & 1.458 & 1.865 & 1.151 & 1.055 & 1.379 & 1.328 \\
\hline $10^{-8} \mathrm{M}$ & 1.250 & 1.191 & 1.685 & 1.555 & 1.169 & 1.159 & 1.545 & 1.488 \\
\hline $10^{-6} \mathrm{M}$ & 1.265 & 1.189 & 1.736 & 1.613 & 1.167 & 1.139 & 1.560 & 1.490 \\
\hline Standard error & 0.024 & 0.017 & 0.060 & 0.045 & 0.016 & 0.026 & 0.013 & 0.021 \\
\hline$P$ value & NS & NS & $<0.01$ & $<0.01$ & NS & $<0.05$ & $<0.001$ & $<0.001$ \\
\hline
\end{tabular}

Note that progesterone has the most pronounced effect. The differences of the tabulated mean values from 1.0 represent the proportionate changes corresponding to the treatment levels.

Table 2 Demonstration of the effects of the time of exposure to oestrogen and progesterone stimulation on MUC1 production in HEC1A and HEC1B cells using flow cytometric analysis and HMFG1 and CT1 (independent of concentration).

\begin{tabular}{|c|c|c|c|c|c|c|c|c|}
\hline & \multicolumn{4}{|c|}{ HEC1A cell line } & \multicolumn{4}{|c|}{ HEC1B cell line } \\
\hline & \multicolumn{2}{|c|}{ Oestrogen } & \multicolumn{2}{|c|}{ Progesterone } & \multicolumn{2}{|c|}{ Oestrogen } & \multicolumn{2}{|c|}{ Progesterone } \\
\hline & HMFG1 & CT1 & HMFG1 & CT1 & HMFG1 & $\mathrm{CT} 1$ & HMFG1 & CT1 \\
\hline \multicolumn{9}{|c|}{ Treatment duration } \\
\hline $48 \mathrm{~h}$ & 1.231 & 1.175 & 1.367 & 1.317 & 1.084 & 1.082 & 1.293 & 1.210 \\
\hline $72 \mathrm{~h}$ & 1.194 & 1.147 & 1.482 & 1.413 & 1.138 & 1.080 & 1.350 & 1.317 \\
\hline $96 \mathrm{~h}$ & 1.253 & 1.170 & 1.735 & 1.583 & 1.161 & 1.133 & 1.637 & 1.571 \\
\hline $192 \mathrm{~h}$ & 1.342 & 1.268 & 1.922 & 1.732 & 1.268 & 1.176 & 1.697 & 1.644 \\
\hline Standard error & 0.028 & 0.019 & 0.069 & 0.052 & 0.019 & 0.030 & 0.015 & 0.025 \\
\hline$P$ value & $<0.05$ & $<0.01$ & $<0.001$ & $<0.001$ & $<0.001$ & NS & $<0.001$ & $<0.001$ \\
\hline
\end{tabular}

The differences of the tabulated mean values from 1.0 represent the proportionate changes corresponding to the treatment levels. 
Table 3 MUC1 (HMFG1) expression in HEC1B cells. Demonstration of the interaction between sex steroid hormone concentration and duration of treatment when HEC1B cells were treated with progesterone and MUC1 expression was examined using HMFG1.

\begin{tabular}{lllll}
\hline & \multicolumn{4}{c}{ Duration of treatment } \\
\cline { 2 - 5 } & $48 \mathrm{~h}$ & $72 \mathrm{~h}$ & $96 \mathrm{~h}$ & $192 \mathrm{~h}$ \\
\hline Progesterone concentration & & & & \\
$10^{-10} \mathrm{M}$ & 1.202 & 1.337 & 1.460 & 1.517 \\
$10^{-9} \mathrm{M}$ & 1.322 & 1.342 & 1.745 & 1.770 \\
$10^{-6} \mathrm{M}$ & 1.357 & 1.372 & 1.707 & 1.803 \\
\hline
\end{tabular}

Increasing progesterone concentration and treatment time almost doubled the expression of the MUC1 glycoform detected by this Mab (1.803-fold increase with $10^{-6} \mathrm{M}$ progesterone after $192 \mathrm{~h}$,

$P<0.001)$. The differences between the tabulated mean values and 1.0 represent the proportionate changes corresponding to the treatment levels.

line was of a similar heterogeneity. HEC1B cells showed the strongest expression pattern (Fig. 1B-E). Like Ishikawa cells, the cells appeared to express MUC1 in a homogenous pattern.

\section{Flow cytometry for quantitative analysis of MUC1 production in stimulated endometrial epithelial cell lines}

Flow cytometric analysis of MUC1 protein production using HMFG1 and CT1 in HEC1A cells incubated with 17-beta oestradiol showed no evidence of a treatment effect with the range of concentrations used. There was a minimal increase in MUC1 production with increased time of exposure to 17-beta oestradiol, which was strongest after $48 \mathrm{~h}$ (reaching a maximum of a 1.342-fold increase at $192 \mathrm{~h}$ with HMFG1, $P<0.05)$. Addition of progesterone was associated with an increase in expression of MUC1 in HEC1A cells, as demonstrated by HMFG1 and CT1 (Tables 1 and 2, Fig. 2). A consistent response to progesterone was seen. Although there was some variation in magnitude with each antibody, the increases in MUC1 expression observed using HMFG1 (which detects the glycosylated ectodomain of MUC1) and that observed by CT1 (which detects the cytoplasmic tail), were very similar. The treatment effect was relatively small at $48 \mathrm{~h}$ but increased with the passage of time. A 1.922-fold increase was demonstrated with HMFG1 after progesterone exposure of $192 \mathrm{~h}$, independent of treatment concentration $(P<0.001)$. This suggested that the MUC1 core protein detected by $\mathrm{CT} 1$, and the MUC1 glycoform detected by HMFG1, were both up-regulated by the addition of progesterone in HEC1A cells.

Analysis of MUC1 protein production using flow cytometry and the same MUC1 Mabs in HEC1B cells produced similar results (Tables 1 and 2, Fig. 3). There was little effect on MUC1 expression with the addition of 17-beta oestradiol, even with increasing concentrations. There was a small but significant effect with time

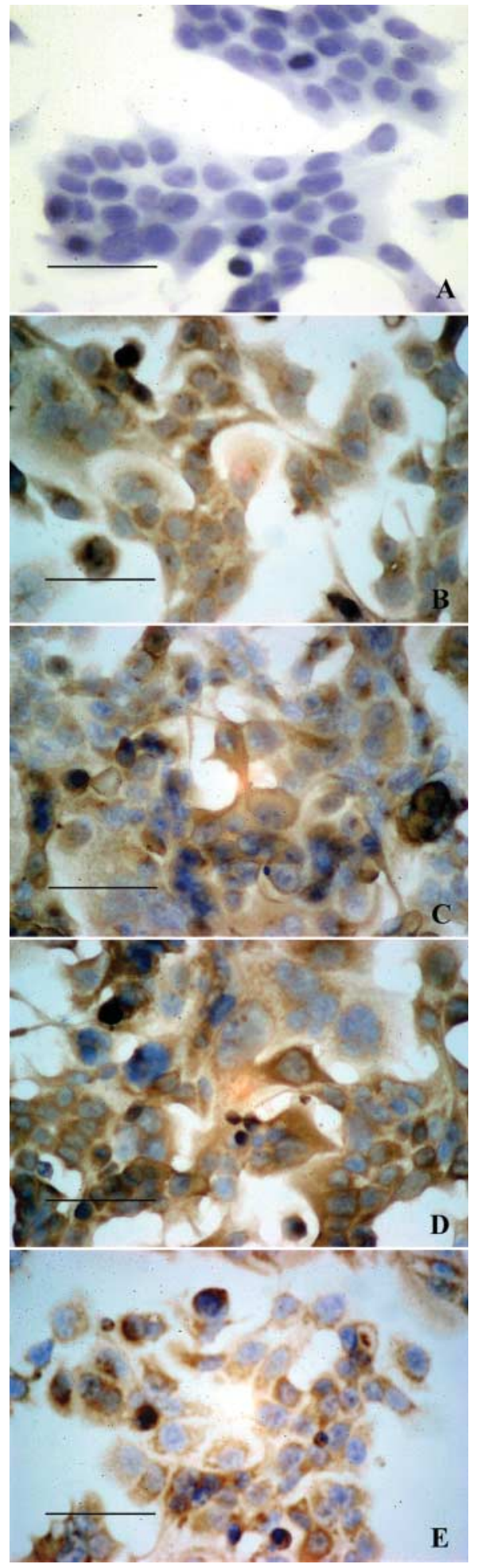

Figure $1 \mathrm{MUC1}$ staining of untreated HEC1B cells. (A) Negative control, (B) CT1, (C) HMFG1, (D) HMFG2 and (E) SM3. CT1, HMFG, HMFG2 and SM3 show strong and homogenous cytoplasmic staining with nuclear sparing. SM3 shows the least intense staining of the MUC1 antibodies. Scale bars, $20 \mu \mathrm{m}$. 
MUC1 expression (HMFG1) in HEC1A cells treated following progesterone treatment

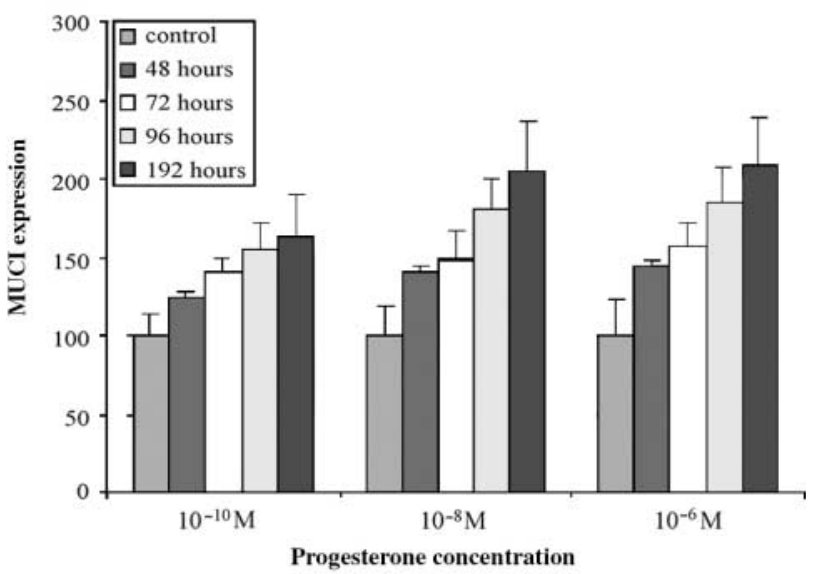

MUC1 expression (CT1) in HEC1A cells following progesterone treatment

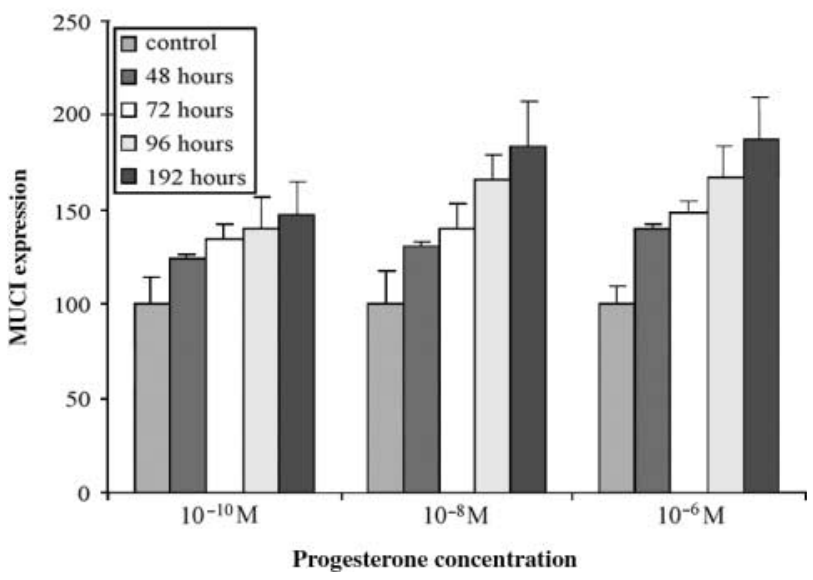

Figure 2 Graphical representation of flow cytometric analyses for MUC1 production, using the MUC1 Mabs HMFG1 and CT1, of the HEC1A cell line after treatment with progesterone (at $10^{-10}, 10^{-8}$ and $10^{-6} \mathrm{M}$ ). Note that progesterone up-regulates MUC1 (a 1.922fold increase was demonstrated with HMFG1 after progesterone exposure of $192 \mathrm{~h}$, independent of treatment concentration, $P<0.001)$.

(reaching a maximum of a 1.268-fold increase in expression at $192 \mathrm{~h}, P<0.001)$.

Progesterone again produced a significant increase in MUC1 expression determined with both HMFG1 and CT1 in HEC1B cells. Although little effect was seen until after $48 \mathrm{~h}$, the two factors, time and treatment, independently increased MUC1 production. There was only evidence of an interaction between sex steroid hormone concentration and duration of treatment when the HEC1B cells were treated with progesterone and MUC1 expression was examined using HMFG1 (Table 3). Increasing progesterone concentration and treatment time almost doubled the expression of the MUC1 glycoform detected by this Mab (1.803-fold increase with $10^{-6} \mathrm{M}$ progesterone after 192 h, $P<0.001)$.
MUC1 expression (HMFG1) in HEC1B cells following progesterone treatment

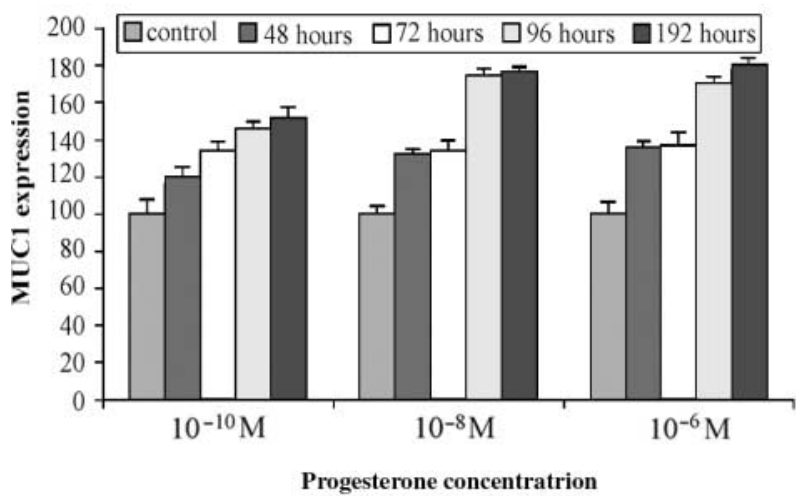

MUC1 expression (CT1) in HEC1B cells following progesterone treatment

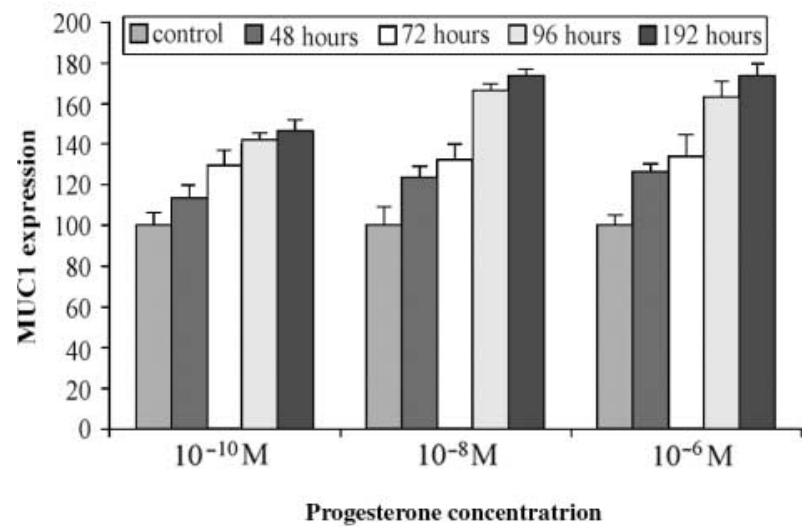

Figure 3 Graphical representation of flow cytometric analyses for MUC1 production, using the MUC1 Mabs HMFG1 and CT1, of the HEC1B cell line after treatment with progesterone (at $10^{-10}, 10^{-8}$ and $\left.10^{-6} \mathrm{M}\right)$. Note that progesterone up-regulates MUC1 similar to the effect seen in HEC1A cells (a 1.697-fold increase was demonstrated with HMFG1 after progesterone exposure of $192 \mathrm{~h}$, independent of treatment concentration, $P<0.001$ ).

In both cell lines, when progesterone was introduced after $96 \mathrm{~h}$ of treatment with 17-beta oestradiol the level of MUC1 expression, as demonstrated by HMFG1 and CT1, showed an equivalent increase to treatment with progesterone alone. Oestrogen priming did not appear to increase the progestogenic effect.

IL-1 $\beta$ appeared to have no effect on MUC1 expression in either cell line treated with this combination of sex steroids at either 10 or $100 \mathrm{pg} / \mathrm{ml}$.

\section{Analysis of MUC1 promoter activity in stimulated endometrial epithelial cell lines using a CAT enzyme immunoassay}

The effect of the sex steroid hormone regimes on MUC1 promoter activity was analysed using a previously described MUC1 promoter construct linked to the CAT reporter gene (Kovarik et al. 1993). The relative level of CAT activity in treated cells versus an untreated control 
was then used to estimate effects on transcriptional activity of the MUC1 gene.

CAT activity, and thus MUC1 promoter activity, was only very slightly affected by treatment with oestrogen in both HEC1A and HEC1B cells (Fig. 4). Progesterone treatment, however, significantly increased MUC1 promoter activity in these cell lines $(1.8$-fold $(P=0.001)$ and 2.27 -fold $(P<0.01)$ in HEC1A and HEC1B cells respectively) (Fig. 4). This was also reflected in the cells treated with progesterone with prior oestrogen priming (Fig. 4). HEC1B cells showed a 3.35 -fold $(P<0.01)$ increase in activity after this combination of treatment. IL-1 $\beta$ appeared to have a small, but contradictory, effect on promoter activity (Fig. 4). There was a slight increase in activity after treatment in HEC1A cells and a slight decrease in HEC1B cells (not significant).

\section{Discussion}

This study demonstrates that progesterone alone, or when applied after a previous oestrogen stimulus, up-regulates MUC1 protein expression in two human cell lines derived from endometrial epithelial carcinoma cells. It also shows that MUC1 is a hormone responsive, or more specifically progesterone responsive, gene. This correlates strongly with other in vivo reports of the normal endometrial epithelium. A recent study in patients undergoing oocyte donation showed that patients treated with 17-beta oestradiol plus progesterone for 6 days exhibited a significantly higher increase in MUC1 mRNA production compared with those treated with 17-beta oestradiol alone (Meseguer et al. 2001). Previous observations in natural cycles and in the rabbit confirm this effect (Hey et al. 1994, Hoffman et al. 1998). Thus, our results suggest that the HEC1A and HEC1B endometrial carcinoma cell lines are useful for studying the hormonal mechanisms controlling transcription and translation of MUC1.

Hormonal regulation of MUC1 has been demonstrated in a number of other organ systems. In human breast carcinoma cell lines, oestrogen and progesterone stimulation is associated with increased MUC1 mucin expression, and a similar effect has been demonstrated in human prostate carcinoma cell lines in response to medroxyprogesterone acetate and androgens (McGuckin et al. 1998, Mitchell et al. 2002). However, although MUC1 protein is up-regulated by progesterone in breast carcinoma cell lines, MUC1 mRNA levels do not appear to vary following oestrogen or progesterone treatment (either singly or in combination) (Botti et al. 1997). It has therefore been postulated that, in breast carcinoma, increased MUC1 protein production is due to a post-transcriptional mechanism. Yet, in the normal endometrium, MUC1 mRNA is increased when the serum level of progesterone is at its highest, in the mid-secretory phase (Hey et al. 1994). In our study, MUC1 promoter activity was analysed in endometrial cells, using a previously described MUC1 promoter construct linked to the CAT reporter gene, and was regulated

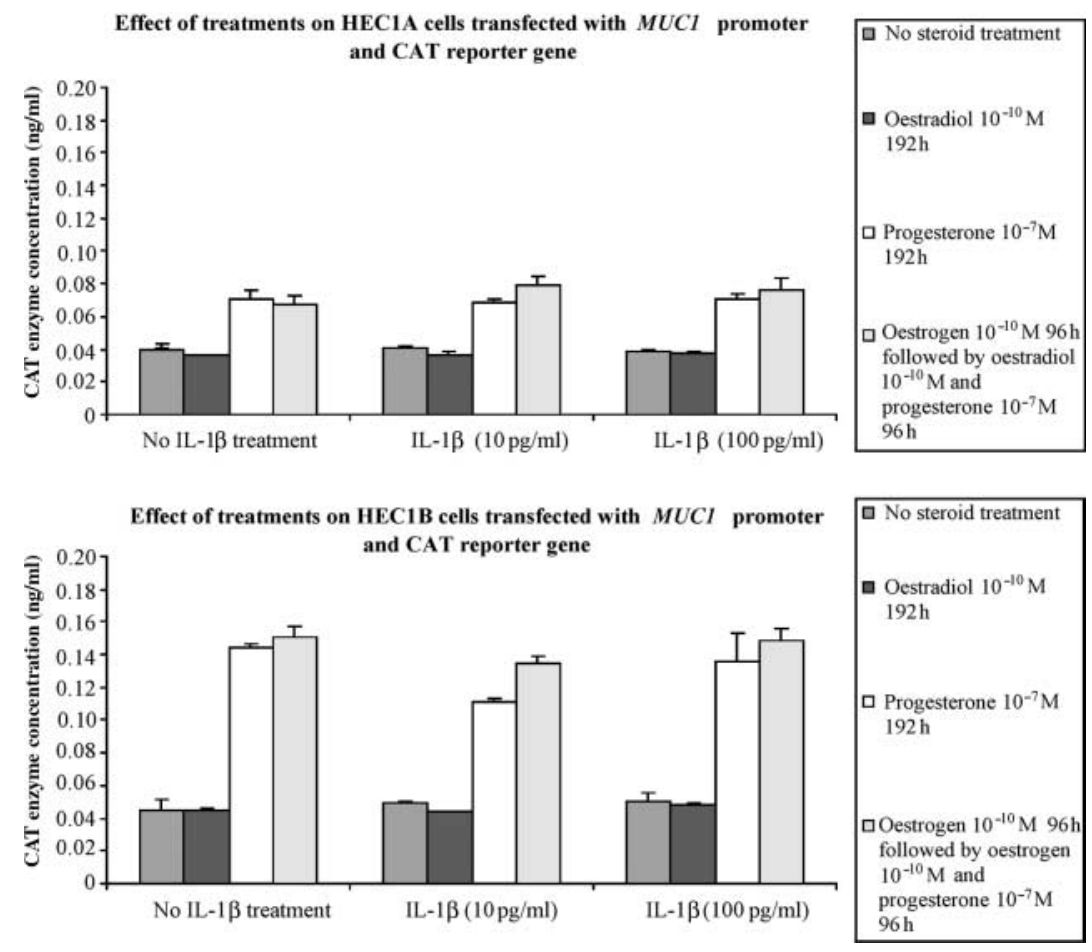

Figure 4 Graphical representation of the effect of sex steroid hormones and IL-1 $\beta$ on MUC1 promoter activity in HEC1A and HEC1B cells. The effect of the sex steroid hormones and IL-1 $\beta$ regimes on MUC1 promoter activity was analysed using a MUC1 promoter construct linked to the CAT reporter gene. The relative level of CAT activity in treated cells versus an untreated control was then used to estimate whether a treatment affected transcriptional activity in the MUC1 gene. 
by progesterone. Our data suggest that progesterone controls transcription of the MUC1 gene in endometrial epithelial cells, in vitro, consistent with observations in vivo (Kovarik et al. 1993). However, it raises questions regarding the mechanisms by which progesterone regulates MUC1 protein as we have shown that progesterone treatment increased MUC1 transcription in both PR-positive HEC1A cells, and PR-negative HEC1B cells. This finding was somewhat surprising given the well-documented evidence that hormonal steroids modulate transcription by activation of their cognate receptor (Evans 1988, Beato 1989, Mitchell et al. 2002). Certainly, on the basis of results with HEC1B, the regulation of the MUC1 gene by progesterone seems to be independent of PR status.

In most tissues, oestrogen controls the regulation of PR, thereby also controlling sensitivity to progestins (Bouchard 1999). Our results showed that oestrogen priming did not enhance the progesterone effect on MUC1 in the PR-positive cells, suggesting that PR levels were not affected by stimulation with oestrogen. Furthermore, prior oestrogen stimulation did not induce PR in either cell line at the immunohistochemical level. This provides further evidence that the regulation of MUC1 production by progesterone may not conform to the traditional model of steroid hormone action.

Non-receptor-mediated effects of sex steroids have been demonstrated in a number of studies (Bouchard 1999, Falkenstein \& Wehling 2000). A recent report showed that oestrogen-mediated activation of adenyl cyclase and CAMP occurred independently of ERs, via a G-protein-coupled receptor (GPCR), to control the level of extracellular signal-regulated kinases in the epidermal growth factor (EGF) receptor-MAPK pathway (Filardo et al. 2002). This was consistent with reports that have implicated GPCRs in rapid membrane signalling events mediated by oestrogen and progesterone (Machelon et al. 1996, Rosner et al. 1999, Falkenstein \& Wehling 2000). Given the importance of the protein kinase A pathway in mediating uterine differentiation of steroid hormone action, this non-classical pathway is worthy of further investigation.

Another possibility is that MUC1 production is mediated by a non-genomic pathway via a membrane receptor. A recent study describes the cloning of a cDNA from spotted seatrout ovaries encoding a protein that satisfies a number of criteria for its designation as a steroid membrane receptor: plausible structure, tissue specificity, cellular distribution, steroid binding, signal transduction, hormonal regulation and biological relevance (Zhu et al. 2003a). Genes homologous to this fish membrane progestin receptor have subsequently been identified and partially characterised in humans (Zhu et al. 2003 b).

Alternatively, it is possible that the progesterone effect is mediated via the genomic pathway, but not via PRA or PRB, rather via another PR isoform (Wei et al. 1997). PR also exists as PRC, a smaller N-terminally truncated progestin-specific binding protein that would not be detected by the Mab used in our study, and PRC has been shown to be regulated by progestins and anti-progestins (Wei et al. 1997). Furthermore, the PRA and PRB levels in the HEC1B cells may be so low that they cannot be detected using Western blot analysis; detection may require a technique, such as RT-PCR, that is more sensitive to very small amounts of product. Similarly, it is also possible that the progesterone effect is mediated via the androgen receptor (AR). Ligand activation of AR is the mechanism by which androgens up-regulate MUC1 protein (Mitchell et al. 2002). AR has been shown to be regulated by progestins in human breast cancer cells (Bentell et al. 1999, GarciaBecerra et al. 2004), and AR expression has been demonstrated in HEC1A and HEC1B cells ( $\mathrm{K}$ Bumhaid, personal communication).

Exposure to the candidate embryonic MUC1 modulator, IL-1 $\beta$, had no effect on MUC1 at either the protein or the transcriptional level in this study. There are a number of possible explanations for this observation. The levels of and duration of exposure to the cytokine may have not been appropriate. Only two MUC1 Mabs were used and it is possible that IL-1 $\beta$ does affect MUC1 but only at the level of post-translational modification, by affecting the glycoform pattern of MUC1. The IL-1 receptor (type 1) (IL$1 R$ t1) status of either cell line is not known and, if these cell lines are IL-1R t1 negative, an effect might not be seen. This latter explanation, however, seems unlikely as there are a number of reports of proteins being regulated by IL-1 $\beta$ in other endometrial epithelial carcinoma cell lines, such as RL952 and Ishikawa (Moghul et al. 1994, Makrigiannakis et al. 1999). In addition, there are similar reports of IL-1 $\beta$ regulating gene and protein expression in endometrial stromal cells (Huang et al. 1998, Tsai et al. 2001). It is therefore possible that, in the endometrium, IL-1 $\beta$ could regulate MUC1 by generating a signal from the underlying stromal compartment.

In summary these observations provide evidence for upregulation of MUC1 protein expression at the transcriptional level in the human endometrial epithelium. Given that over-expression of MUC1 could potentially be associated with infertility and failure of embryo implantation, progesterone-dependent regulation of MUC1 may be important in determining endometrial receptivity and other normal physiological processes.

\section{Acknowledgements}

This work was performed at the Institute of Developmental and Reproductive Biology, Imperial College, Hammersmith Hospital, Du Cane Road, London W12 0NN, UK.

This work was supported by a grant from the Medical Research Council (G84/5342). Statistical advice was kindly provided by Dr Eurof Walters, Statistical Consultant, Cambridge, UK. The authors would like to thank Professor Hilary Critchley and Dr Anita Abdul-Aziz for their advice and encouragement. The authors declare that there is no conflict of interest that would prejudice the impartiality of this scientific work. 


\section{References}

Abe M \& Kufe D 1993 Characterization of cis-acting elements regulating transcription of the human DF3 breast carcinoma-associated antigen (MUC1) gene. PNAS 90 282-286.

Alam J \& Cook JL 1990 Reporter genes: application to the study of mammalian gene transcription. Analytical Biochemistry $\mathbf{1 8 8}$ 245-254.

Aplin JD 1997 Adhesion molecules in implantation. Reviews in Reproduction 2 84-93.

Bamberger AM, Bamberger CM, Gellersen B \& Schulte HM 1996 Modulation of AP-1 activity by the human progesterone receptor in endometrial adenocarcinoma cells. PNAS 93 6169-6174.

Baranao RI, Piazza A, Rumi LS \& Polak de Fried E 1997 Determination of IL-1 and IL-6 levels in human embryo culture-conditioned media. American Journal of Reproduction and Immunology 37 191-194.

Beato M 1989 Gene regulation by steroid hormones. Cell $\mathbf{5 6}$ 335-344.

Bentel JM, Birrell SN, Pickering MA, Holds DJ, Horsfall DJ \& Tilley WD 1999 Androgen receptor agonist activity of the synthetic progestin, medroxyprogesterone acetate, in human breast cancer cells. Molecular and Cellular Endocrinology 154 11-20.

Botti C, Seregni E, Lombardo C, Massaron S \& Bombardieri E 1997 Effects of steroid-free fetal serum and steroid supplementation on MUC1 gene expression in human breast cancer cell line MCF7. Anticancer Research 17 205-208.

Bouchard P 1999 Progesterone and the progesterone receptor. Journal of Reproductive Medicine 44 Suppl 153-157.

Brayman M, Thathiah A \& Carson DD 2004 MUC1: a multifunctional cell surface component of reproductive tissue epithelia. Reproduction Biology and Endocrinology 24.

Burchell J \& Taylor-Papadimitriou J 1993 Effect of modification of carbohydrate side chains on the reactivity of antibodies with coreprotein epitopes of the MUC1 gene product. Epithelial Cell Biology 2 155-162.

Cannon JG \& Dinarello CA 1985 Increased plasma interleukin-1 activity in women after ovulation. Science 227 1247-1249.

DeLoia JA, Krasnow JS, Brekosky J, Babaknia A, Julian J \& Carson DD 1998 Regional specialisation of the cell membrane-associated, polymorphic mucin (MUC 1) in human uterine epithelia. Human Reproduction 13 2902-2909.

Evans RM 1988 The steroid and thyroid hormone receptor superfamily. Science 240 889-895.

Falkenstein E \& Wehling M 2000 Nongenomically initiated steroid actions. European Journal of Clinical Investigation 3 51-54.

Filardo EJ, Quinn JA, Frackelton AR Jr \& Bland KI 2002 Estrogen action via the $G$ protein-coupled receptor, GPR30: stimulation of adenylyl cyclase and cAMP-mediated attenuation of the epidermal growth factor receptor-to-MAPK signaling axis. Molecular Endocrinology 16 70-84.

Gao JG, Mazella J, Powell DR \& Tseng L 1994 Identification of a distal regulatory sequence of the human IGFBP-1 gene promoter and regulation by the progesterone receptor in a human endometrial adenocarcinoma cell line. DNA Cell Biology 13 829-837.

Garcia-Becerra R, Cooney AJ, Borja-Cacho E, Lemus AE, PerezPalacios G \& Larrea F 2004 Comparative evaluation of androgen and progesterone receptor transcription selectivity indices of 19-nortestosterone-derived progestins. Journal of Steroid Biochemistry and Molecular Biology 91 21-27.

Giri DD, Goepel JR, Rogers K \& Underwood JC 1988 Immunohistological demonstration of progesterone receptor in breast carcinomas: correlation with radioligand binding assays and oestrogen receptor immunohistology. Journal of Clinical Pathology $\mathbf{4 1}$ 444-447.

Gollub EG, Goswami S, Kouba D \& Marom Z 1993 Regulation of mucin gene expression in secretory epithelial cells. Biochemical and Biophysical Research Communications 197 667-673.
Gollub EG, Waksman H, Goswami S \& Marom Z 1995 Mucin genes are regulated by estrogen and dexamethasone. Biochemical and Biophysical Research Communications 217 1006-1014.

Hey NA, Graham RA, Seif MW \& Aplin JD 1994 The polymorphic epithelial mucin MUC1 in human endometrium is regulated with maximal expression in the implantation phase. Journal of Clinical and Endocrinological Metabolism 78 337-342.

Hilkens J, Buijs F, Hilgers J, Hageman P, Calafat J, Sonnenberg A \& van der Valk M 1984 Monoclonal antibodies against human milkfat globule membranes detecting differentiation antigens of the mammary gland and its tumors. International Journal of Cancer $\mathbf{3 4}$ 197-206.

Ho JJ, Cheng S \& Kim YS 1995 Access to peptide regions of a surface mucin (MUC1) is reduced by sialic acids. Biochemical and Biophysical Research Communications 210 866-873.

Hoffman LH, Olson GE, Carson DD \& Chilton BS 1998 Progesterone and implanting blastocysts regulate Muc1 expression in rabbit uterine epithelium. Endocrinology 139 266-271.

Horne AW, White JO \& Lalani E-N 2002a Adhesion molecules and the normal endometrium. British Journal of Obstetics and Gynaecology 109 610-617.

Horne AW, White JO, Lalani el-N, Mobberley MA, Margara RA, Trew GH \& Ryder T 2002b Analysis of epitopes on endometrial epithelium by scanning immunoelectron microscopy. Biochemical and Biophysical Research Communications 292 102-108.

Huang JC, Liu DY, Yadollahi S, Wu KK \& Dawood MY 1998 Interleukin-1 beta induces cyclooxygenase-2 gene expression in cultured endometrial stromal cells. Journal of Clinical Endocrinology \& Metabolism 83 538-541.

Kovarik A, Peat N, Wilson D, Gendler SJ \& Taylor-Papadimitriou J 1993 Analysis of the tissue-specific promoter of the MUC1 gene. Journal of Biological Chemistry 268 9917-9926.

Kovarik A, Lu PJ, Peat N, Morris J \& Taylor-Papadimitriou J 1996 Two GC boxes (Sp1 sites) are involved in regulation of the activity of the epithelium-specific MUC1 promoter. Journal of Biological Chemistry 271 18140-18147.

Kuramoto H 1972 Studies of the growth and cytogenetic properties of human endometrial adenocarcinoma in culture and its development into an established line. Acta Obstetrica Gynaecologica Japonica 19 47-58.

Kuramoto H, Tamura S \& Notake Y 1972 Establishment of a cell line of human endometrial adenocarcinoma in vitro. American Journal of Obstetics and Gynecology 114 1012-1019.

Lancaster CA, Peat N, Duhig T, Wilson D, Taylor-Papadimitriou J \& Gendler SJ 1990 Structure and expression of the human polymorphic epithelial mucin gene: an expressed VNTR unit. Biochemical and Biophysical Research Communications 173 1019-1029.

McGuckin M, Quin RJ \& Ward BG 1998 Progesterone stimulates production and secretion of MUC1 epithelial mucin in steroid-responsive breast cancer cell lines. International Journal of Oncology 12 939-945.

Machelon V, Nome F, Grosse B \& Lieberherr M 1996 Progesterone triggers rapid transmembrane calcium influx and/or calcium mobilization from endoplasmic reticulum, via a pertussis-insensitive G-protein in granulosa cells in relation to luteinization process. Journal of Cell Biochemistry 61 619-628.

Makrigiannakis A, Margioris AN, Zoumakis E, Stournaras C \& Gravanis A 1999 The transcription of corticotropin-releasing hormone in human endometrial cells is regulated by cytokines. Neuroendocrinology 70 451-459.

Meseguer M, Aplin JD, Caballero-Campo P, O'Connor JE, Martin JC, Remohi J, Pellicer A \& Simon C 2001 Human endometrial mucin MUC1 is up-regulated by progesterone and down-regulated in vitro by the human blastocyst. Biology of Reproduction 64 590-601.

Mitchell S, Abel P, Madaan S, Jeffs J, Chaudhary K, Stamp G \& Lalani el-N 2002 Androgen-dependent regulation of human MUC1 mucin expression. Neoplasia 4 9-18. 
Moghul A, Lin L, Beedle A, Kanbour-Shakir A, DeFrances MC, Liu Y \& Zarnegar R 1994 Modulation of c-MET proto-oncogene (HGF receptor) mRNA abundance by cytokines and hormones: evidence for rapid decay of the $8 \mathrm{~kb}$ c-MET transcript. Oncogene 9 2045-2052.

Morris JR \& Taylor-Papadimitriou J 2001 The Sp1 transcription factor regulates cell type-specific transcription of MUC1. DNA Cell Biology 20 133-139.

Nishida M, Kasahara K, Kaneko M, Iwasaki H \& Hayashi K 1985 Establishment of a new human endometrial adenocarcinoma cell line, Ishikawa cells, containing estrogen and progesterone receptors. Nippon Sanka Fujinka Gakkai Zasshi 37 1103-1111.

Pemberton L, Taylor-Papadimitriou J \& Gendler SJ 1992 Antibodies to the cytoplasmic domain of the MUC1 mucin show conservation throughout mammals. Biochemical and Biophysical Research Communications 185 167-175.

Peterson CM 2000 Estrogen and progesterone receptors: an overview from the year 2000. Journal of the Society for Gynecological Investigations $7 \mathrm{~S} 3-\mathrm{S} 7$.

Price MR, Sekowski M \& Gendler SJ 1991 Purification of anti-epithelial mucin monoclonal antibodies by epitope affinity chromatography. Journal of Immunological Methods 139 83-90.

Rosner W, Hryb DJ, Khan MS, Nakhla AM \& Romas NA 1999 Androgen and estrogen signalling at the cell membrane via G-proteins and cyclic adenosine monophosphate. Steroids 64 100-106.

Simon C \& Valbuena D 1999 Embryonic implantation. Annals of Endocrinology 60 134-136.

Simon C, Pellicer A \& Polan ML 1995 Interleukin-1 system crosstalk between embryo and endometrium in implantation. Human Reproduction 10 (Suppl 2) 43-54.

Simon C, Valbuena D, Krussel J, Bernal A, Murphy CR, Shaw T, Pellicer A \& Polan ML 1998 Interleukin-1 receptor antagonist prevents embryonic implantation by a direct effect on the endometrial epithelium. Fertility and Sterility 70 896-906.

Simon C, Martin JC, Meseguer M, Caballero-Campo P, Valbuena D \& Pellicer A 2000 Embryonic regulation of endometrial molecules in human implantation. Journal of Reproduction and Fertility Supplement $\mathbf{5 5}$ 43-53.

Sivridis E, Giatromanolaki A, Koukourakis MI, Georgiou L \& Anastasiadis P 2002 Patterns of episialin/MUC1 expression in endometrial carcinomas and prognostic relevance. Histopathology $\mathbf{4 0} 92-100$.
Taylor-Papadimitriou J, Peterson JA, Arklie J, Burchell J, Ceriani RL \& Bodmer WF 1981 Monoclonal antibodies to epithelium-specific components of the human milk fat globule membrane: production and reaction with cells in culture. International Journal of Cancer 28 17-21.

Tsai SJ, Wu MH, Lin CC, Sun HS \& Chen HM 2001 Regulation of steroidogenic acute regulatory protein expression and progesterone production in endometriotic stromal cells. Journal of Clinical Endocrinology and Metabolism 86 5765-5773.

Way DL, Grosso DS, Davis JR, Surwit EA \& Christian CD 1983 Characterization of a new human endometrial carcinoma (RL95-2) established in tissue culture. In Vitro 19 147-158.

Wei LL, Norris BM \& Baker CJ 1997 An N-terminally truncated third progesterone receptor protein, $\mathrm{PR}(\mathrm{C})$, forms heterodimers with $\mathrm{PR}(\mathrm{B})$ but interferes in $\mathrm{PR}(\mathrm{B})-\mathrm{DNA}$ binding. Journal of Steroid Biochemistry and Molecular Biology 62 287-297.

Xing PX, Tjandra JJ, Stacker SA, Teh JG, Thompson CH, McLaughlin PJ \& McKenzie IF 1989 Monoclonal antibodies reactive with mucin expressed in breast cancer. Immunology and Cell Biology 67 $183-195$

Zaretsky JZ, Sarid R, Aylon Y, Mittelman LA, Wreschner DH \& Keydar I 1999 Analysis of the promoter of the MUC1 gene overexpressed in breast cancer. FEBS Letters $\mathbf{4 6 1}$ 189-195.

Zhu Y, Bond J \& Thomas P 2003a Identification, classification, and partial characterization of genes in humans and other vertebrates homologous to a fish membrane progestin receptor. PNAS $\mathbf{1 0 0}$ 2237-2242.

Zhu Y, Rice CD, Pang Y, Pace M \& Thomas P 2003b Cloning, expression, and characterization of a membrane progestin receptor and evidence it is an intermediary in meiotic maturation of fish oocytes. PNAS 100 2231-2236.

Zolti M, Ben-Rafael Z, Meirom R, Shemesh M, Bider D, Mashiach S \& Apte RN 1991 Cytokine involvement in oocytes and early embryos. Fertility and Sterility 56 265-272.

Received 15 July 2005

First decision 12 September 2005

Revised manuscript received 14 November 2005

Accepted 25 November 2005 